\title{
Measuring energy usage and sustainability development in Asian nations by DEA intermediate approach
}

Toshiyuki Sueyoshi and Yan Yuan*

${ }^{*}$ Correspondence: margaretmity@gmail.com Management Department, New Mexico Institute of Mining and Technology, 801 Leroy Place, Socorro, NM 87801, USA

\begin{abstract}
This study proposes a new use of data envelopment analysis (DEA) for assessing economic success and environmental protection, so measuring the level of sustainability. The new approach is referred to as "DEA environmental assessment," and it can measure the performance of various entities that use inputs to produce not only desirable outputs but also undesirable outputs. DEA models are generally classified into radial or non-radial category. This study proposes a new "intermediate" approach between them. As an illustrative application, this study is interested in empirical assessment on energy usage and social sustainability of 21 Asian nations from 2008 to 2014. The energy usage, usually classified into primal (e.g., oil and coal) and secondary (i.e., electricity) categories, is essential in developing the economy, but the development simultaneously produces various pollutions (e.g., carbon emission). They have been developing their economic prosperities in a short period, but simultaneously suffering from such pollutions. All Asian nations are classified into four or five groups based upon their unified efficiency measures under natural disposability, where economic performance is the first priority and environmental performance is the second, along with managerial disposability with the opposite priority to the natural disposability. An implication found in this study is that among Asian nations, Japan and New Zealand belong to the first tier in terms of developing their social sustainability. Japan's economy started to turn down after 2012 and faced a pitfall in recent years. Meanwhile, New Zealand has developed its economy by exporting agriculture products and is surrounded by natural beauty. Thus, the two nations are ranked as the top tier under the four types of unified efficiency measures. Beside these expected findings, this study has found that large nations such as China and India have not badly performed if we consider the size of their economies. This is a surprising result because they are large carbon emitters in the world and thereby they have been often criticized by international communities. Their problem is that the living standard of people is low because of the size of population. The empirical findings are useful in developing the energy and industrial policies of Asian nations.
\end{abstract}

Keywords: Data environment analysis, Economy, Environment, Energy

\section{Background}

Intergovernmental Panel on Climate Change (IPCC: http://ipcc.ch/index.htm), established within United Nations (UN) environmental program, reported the policy suggestion in April 2014 that it was necessary for us to reduce an amount of greenhouse gas 
(GHG) emissions, in particular $\mathrm{CO}_{2}$, by $40-70 \%$ (compared with 10 years ago) until 2050 and to reduce them at the level of almost zero by the end of this twenty-first century via shifting the current systems to energy-efficient ones. Otherwise, the IPCC has warned that the global warming and climate change will destroy our natural and socioeconomic systems. Consequently, we will face various risks (e.g., heat waves, droughts, floods, food crisis as well as damages to human, social and economic systems) on the earth.

A difficulty in attaining such a sustainable society is that we do not have a methodology to properly assess economic development and pollution reduction in a unified manner because the former development has been usually associated with various types of pollutions. To partly deal with the difficulty, data envelopment analysis (DEA) has been used as a methodology for performance assessment on organizations, whose economic activities are characterized by desirable outputs and inputs. A problem was that conventional DEA documented a limited level of practicality in environmental assessment because it did not have a computational scheme to handle an existence of undesirable outputs. To overcome such a difficulty, many research efforts have developed new approaches and related models for DEA environmental assessment which measure the performance of various organizations that produce not only desirable outputs but also undesirable outputs. See recent literature studies such as Sueyoshi and Goto (2018), listing more than 800 previous works. See also Sueyoshi et al. (2017b) for a summary on 693 articles on DEA applied to energy and sustainability and Sueyoshi et al. (2017c) for comparison among radial, non-radial and intermediate approaches in DEA assessment.

In reviewing the previous studies, we find that not many research efforts have examined the performance assessment on energy usage and sustainability in Asian nations even if they have been developing their economic prosperities in a short period, but simultaneously suffering from various pollution problems. In particular, China and India are such good examples of such a rapid development. In contrast, Asia contains many underdeveloped nations such as Bangladesh and North Korea. As a consequence of such existence of large developed and small undeveloped nations, previous DEA studies have not yet explored the relationship between energy usage and sustainability development in Asia.

To measure the sustainability of Asia nations from 2008 to 2014, this study proposes a new use of a DEA intermediate approach, analytically locating between conventional (radial and non-radial) approaches. Using the new approach, this study is interested in measuring how to improve the level of sustainability in Asian from an efficient usage of their primary and secondary energies. That is the purpose of this research.

The remainder of this study is organized as follows: Sect. 2 reviews previous research efforts on DEA applied to energy usages in Asia. Section 3 discusses underlying concepts to unify desirable and undesirable outputs, used in the proposed intermediate approach for DEA environmental assessment. Section 4 describes the mathematical structure of the intermediate approach. Section 5 applies it to the sustainability assessment of all Asian nations. Section 6 summarizes this study along with future extensions.

\section{Previous research}

It is known that DEA has been applied for modeling energy efficiency and performance assessment for a long time, especially in recent years. As mentioned previously, there are several studies on Asian countries. Methodically, the previous works are classified into radial or non-radial models. 
The radial models were most utilized in Tun and Kang (2015), Honma and $\mathrm{Hu}$ (2008, 2014) and Ulah et al. (2016). For example, Ulah et al. (2016) investigated energy or productive efficiency in Australia, New Zealand, China, Taiwan, South Korea, Philippines, India, Myanmar, Japan and Pakistan. Sun et al. (2013) extended the radial model for performance evaluation and ranking on Asian lead frame firms and flexible manufacturing systems.

The non-radial models were used to investigate the performance of Asian countries. For example, Yang et al. (2016) utilized a non-radial model to measure the aggregation of urban input-output efficiency of Taiwan's 22 administrative regions. Hosseinzadeh et al. (2016) identified the importance of a balance of efficiency gains and losses for 33 Australian mining firms by using a bootstrap approach. Li and Lin (2016) used a threestage DEA model to measure the effect of government measures on green productivity growth. Chen (2017) measured the departmental and overall efficiency in Taiwan's counties and cities by applying a multi-activity model. Chaitip et al. (2014) analyzed the production of Thailand's sugarcane by using panel DEA based on a bootstrapping method.

The position of this study is that this study develops a new intermediate approach, analytically locating between radial and non-radial approaches (Sueyoshi and Goto 2012), to examine the level of energy usage and sustainability development of 21 nations in Asia from 2008 to 2014. This study is the first research effort that covers almost all the nations in Asia by utilizing the newly developed intermediate approach. No study has explored the research direction in the previous studies.

\section{Unification between desirable and undesirable outputs}

An important research inquiry is how the proposed approach can unify desirable and undesirable outputs, both of which have opposite directional vectors for performance betterment.

To visually reply to the inquiry, this study prepares Fig. 1, consisting of a single input $(x)$ and two desirable outputs $\left(g_{1}\right.$ and $\left.g_{2}\right)$. The horizontal axis of Fig. 1 is for $g_{1} / x$, and the vertical axis is for $g_{2} / x$. In the case, it is assumed that all DMUs produce the same amount of an undesirable output $(b)$. Meanwhile, Fig. 2 extends it to the case of two undesirable outputs $\left(b_{1}\right.$ and $\left.b_{2}\right)$. The horizontal axis is for $b_{1} / x$ and the vertical axis is for $b_{2} / x$ under the assumption that all DMUs produce the same amount of a desirable output $(g)$. In the two figures, $\{A\},\{B\},\{C\},\{D\}$ and $\{E\}$ indicate the performance of five DMUs. A piece-wise linear contour line $(\{B\}-\{C\}-\{D\}-\{E\})$ indicates an efficiency frontier in each figure.

In the two figures, an inefficient DMU $\{A\}$ directs the location toward a projected point $\left\{A^{\prime}\right\}$ to enhance the joint performance between operational and environmental achievements. The directional vector of desirable outputs is identified as $\left(g_{1}^{A}, g_{2}^{A}\right)$ in Fig. 1 and that of undesirable outputs becomes $\left(-b_{1}^{A},-b_{2}^{A}\right)$ in Fig. 2. The two vector directions $\left(g_{1}^{A}, g_{2}^{A},-b_{1}^{A},-b_{2}^{A}\right)$ are given in examining the performance enhancement of DMU $\{A\}$. However, the magnitude of the two directional vectors is unknown because none knows a distance between $\{A\}$ and $\left\{A^{\prime}\right\}$. It is true that such a magnitude can be visually identified in the two figures. However, if the number of coordinates is more than two, then none knows how to determine the magnitude of a directional vector for performance betterment. A purpose, not all, of DEA environmental assessment is to identify the 


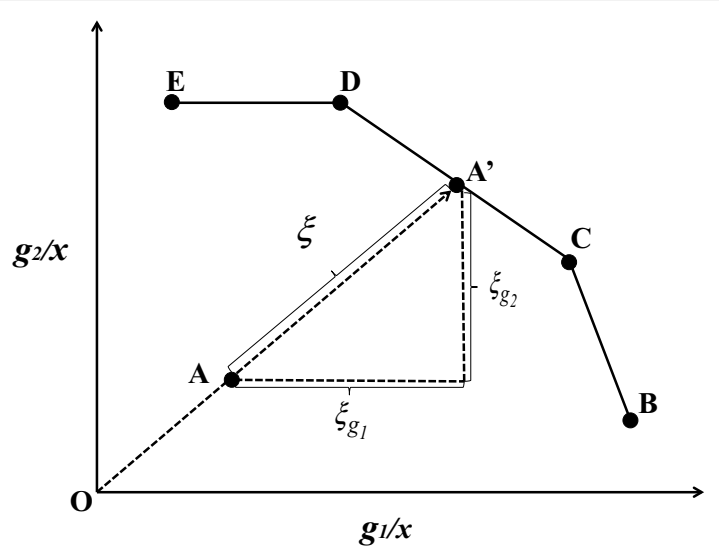

Fig. 1 Projection onto efficiency frontier for desirable outputs. Source: Sueyoshi and Yuan (2017)

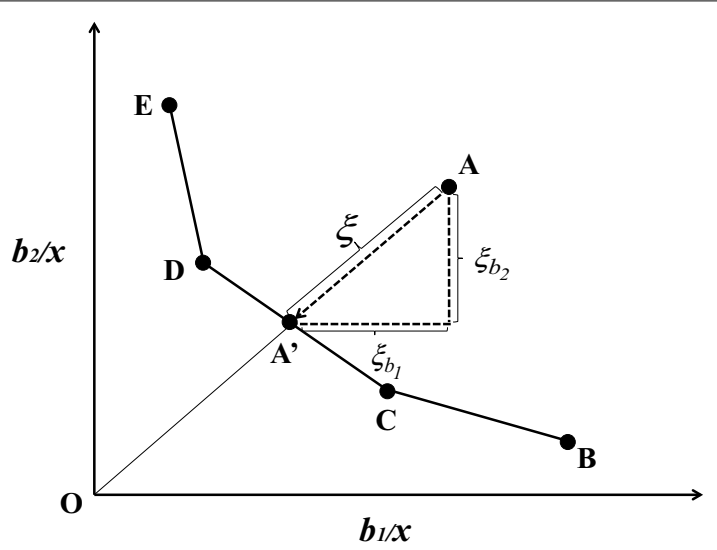

Fig. 2 Projection onto efficiency frontier for undesirable outputs. Source: Sueyoshi and Yuan (2017)

distance between the two points $\left(\{A\}\right.$ and $\left.\left\{A^{\prime}\right\}\right)$ for its relative comparison even in multiple components.

To visually explain the distance measurement, let us consider the ratio $(O A) /\left(O A^{\prime}\right)$ in Fig. 1 that indicates the magnitude of unified efficiency concerning DMU $\{A\}$. The ratio becomes

$$
\frac{O A}{O A^{\prime}}=\frac{O A}{O A+O A^{\prime}}=\frac{1}{1+\frac{A A^{\prime}}{O A}} \cong \frac{1}{1+\frac{A A^{\prime}}{O A^{\prime}}}=\frac{1}{1+\xi}=1-\xi+\xi^{2}-\xi^{3}+\cdots \cong 1-\xi
$$

The above equation considers that DMU $\{A\}$ locates near $\left\{A^{\prime}\right\}$ so that $O A$ can be replaced by $O A^{\prime}$ in the equation. In other words, if a DMU locates on or near an efficiency frontier, then the ratio measure is reliable. In contrast, if the DMU locates far from the efficiency frontier, then the ratio measure may approximate the exact one. The ratio $\left(A A^{\prime} / O A^{\prime}\right)$, or $\xi$ (i.e., a degree of unified inefficiency), indicates the magnitude of a directional vector of $\{A\}$ for improving the operational performance of DMU $\{A\}$, as visually specified in Fig. 1. An approximation error is specified by $\sum_{z=2}^{\infty}(-\xi)^{z}=\xi^{2} /(1+\xi) \cong 0$ because $\xi \leq 1$. Thus, it is acceptable that the measurement of $1-\xi$ can approximate the 
degree of unified efficiency. The proposed approach separates the magnitude of unified inefficiency $(\xi)$ into $\xi_{g_{1}}$ and $\xi_{g_{2}}$ in the case of two components of the inefficiency measure. Such a visual separation is specified in the two coordinates of Fig. 2. Each component functionally corresponds to a slack. Thus, the proposed approach can be considered as "intermediate" between radial and non-radial approaches.

Meanwhile, Fig. 2 depicts another projection of DMU $\{A\}$ in the case of two undesirable outputs $\left(b_{1}\right.$ and $\left.b_{2}\right)$. In this case, our description is a straightforward manner. That is, the ratio $\left(O A^{\prime} / O A\right)$ indicates the degree of unified efficiency of $\{A\}$ by

$$
\frac{O A^{\prime}}{O A}=\frac{O A-A A^{\prime}}{O A}=1-\xi .
$$

The ratio $\left(A A^{\prime} / O A\right)$, or $\xi$, indicates a magnitude of the directional vector of DMU $\{A\}$ to improve the environmental performance in the two undesirable outputs. Thus, it is possible for us to unify desirable and undesirable outputs and to measure the magnitude of unified efficiency by $1-\xi$, as visually discussed in Fig. 2. As mentioned previously in Figs. 1 and 2 also depicts the disaggregation of $\xi$ into two components, $\xi_{b_{1}}$ and $\xi_{b_{2}}$, as visually specified in the two coordinates.

At the end of this section, it is important to note that the level of inefficiency is separated into its components $\left(\xi_{g_{1}}, \xi_{g_{2}}, \xi_{b_{1}}\right.$ and $\left.\xi_{b_{2}}\right)$. This study takes an average of these inefficiency components in formulations for the proposed intermediate model.

\section{Intermediate approach}

\subsection{Formulations under natural disposability}

To explain mathematical formulations for natural and managerial disposability concepts by the proposed intermediate model, this study first considers that there are $n$ DMUs (Decision Making Units: corresponding to an organization to be evaluated). The $j$ th DMU $(j=1, \ldots, n)$ uses a column vector of inputs $\left(X_{j}\right)$ to yield not only a column vector of desirable outputs $\left(G_{j}\right)$ but also a column vector of undesirable outputs $\left(B_{j}\right)$, where they are production factors such as $X_{j}=\left(x_{1 j}, x_{2 j}, \ldots, x_{m j}\right)^{T r}, G_{j}=\left(g_{1 j}, g_{2 j}, . ., g_{s j}\right)^{T r}$ and $B_{j}=\left(b_{1 j}, b_{2 j}, . ., b_{h j}\right)^{T r}$. Here, the superscript " $T r$ " indicates a vector transpose. It is assumed that $X_{j}>0, G_{j}>0$ and $B_{j}>0$ for all $j=1, \ldots, n$. Here, the symbol (>) indicates that all components of the three vectors are strictly positive.

In the proposed formulations, production factors are adjusted by these data ranges in the objective function. The data range adjustments are determined by the upper and lower bounds on inputs and those of desirable and undesirable outputs in the following manner:

(a) $R_{i}^{x}=(m+s+h)^{-1}\left(\max \left\{x_{i j} \mid j=1, \ldots, n\right\}-\min \left\{x_{i j} \mid j=1, \ldots, n\right\}\right)^{-1}$ : a data range adjustment related to the $i$ th input $(i=1, \ldots, m)$,

(b) $R_{r}^{g}=(m+s+h)^{-1}\left(\max \left\{g_{r j} \mid j=1, \ldots, n\right\}-\min \left\{g_{r j} \mid j=1, \ldots, n\right\}\right)^{-1}$ : a data range adjustment related to the $r$ th desirable output $(r=1, \ldots, s)$ and

(c) $R_{f}^{b}=(m+s+h)^{-1}\left(\max \left\{b_{f j} \mid j=1, \ldots, n\right\}-\min \left\{b_{f j} \mid j=1, \ldots, n\right\}\right)^{-1}$ : a data range adjustment related to the $f$ th undesirable output $(f=1, \ldots, h)$.

The purpose of the range adjustment is to avoid an occurrence of zero in dual variables. The occurrence implies that a corresponding production factor(s) is not utilized in the proposed assessment. The empirical result has limited practicality. 
The concept of natural disposability under constant RTS is expressed by the following formulation:

$$
\begin{aligned}
& \text { Maximize } \frac{1}{s+h}\left(\sum_{r=1}^{s} \xi_{r}^{g}+\sum_{f=1}^{h} \xi_{f}^{b}\right)+\varepsilon_{s}\left(\sum_{i=1}^{m} R_{i}^{x} d_{i}^{x-}+\sum_{r=1}^{s} R_{r}^{g} d_{r}^{g}+\sum_{f=1}^{h} R_{f}^{b} d_{f}^{b}\right) \\
& \text { s.t. } \sum_{j=1}^{n} x_{i j} \lambda_{j}+d_{i}^{x-} \quad=x_{i k} \quad(i=1, . ., m), \\
& \sum_{j=1}^{n} g_{r j} \lambda_{j}-d_{r}^{g}-\xi_{r}^{g} g_{r k} \quad=g_{r k} \quad(r=1, . ., s), \\
& \xi_{r}^{g} \quad \leq 1 \quad(r=1, . ., s), \\
& \sum_{j=1}^{n} b_{f j} \lambda_{j}+d_{f}^{b}+\xi_{f}^{b} b_{f k} \quad=b_{f k} \quad(f=1, . ., h), \\
& \xi_{f}^{b} \leq 1 \quad(f=1, . ., h), \\
& \xi_{r}^{g} \geq 0 \quad(r=1, . ., s), \xi_{f}^{b} \geq 0 \quad(f=1, . ., h), \lambda_{j} \quad \geq 0 \quad(j=1, . ., n), \\
& d_{i}^{x-} \geq 0 \quad(i=1, . ., m), d_{r}^{g} \geq 0 \quad(r=1, . ., s) \& d_{f}^{b} \quad \geq 0 \quad(f=1, . ., h) .
\end{aligned}
$$

where $\xi_{r}^{g}(r=1, \ldots, s)$ and $\xi_{f}^{b}(f=1, \ldots, h)$, respectively, stand for subcomponents of an inefficiency score related to desirable and undesirable outputs. Model (1) contains $d_{i}^{x-}$ $(i=1, \ldots, m)$, which indicates an unknown slack variable of the $i$ th input, $d_{r}^{g}(r=1, \ldots, s)$, which indicates an unknown slack variable of the $r$ th desirable output, and $d_{f}^{b}(f=1, \ldots$, $h$ ), which is an unknown slack variable of the $f$ th undesirable output. The $\lambda_{j}$ indicates an unknown column of the $j$ th intensity (or structural) variable. The input slack $+d_{i}^{x-}$ in Model (1) indicates that the $k$ th DMU can attain an efficiency frontier by decreasing the amount of inputs under natural disposability.

A unified efficiency score $\left(\mathrm{UEN}_{c}^{I}\right)$ of the $k$ th DMU under natural disposability is measured by

$\mathrm{UEN}_{c}^{I}=1-\left[\frac{1}{s+h}\left(\sum_{r=1}^{s} \xi_{r}^{g^{*}}+\sum_{f=1}^{h} \xi_{f}^{b^{*}}\right)+\varepsilon_{s}\left(\sum_{i=1}^{m} R_{i}^{x} d_{i}^{x-^{*}}+\sum_{r=1}^{s} R_{r}^{g} d_{r}^{g^{*}}+\sum_{f=1}^{h} R_{f}^{b} d_{f}^{b^{*}}\right)\right]$,

where the superscript (I) indicates an intermediate model under constant (c) RTS.

The dual formulation of Model (1) becomes as follows:

$$
\begin{aligned}
& \operatorname{Minimize} \sum_{i=1}^{m} v_{i} x_{i k}-\sum_{r=1}^{s}\left(u_{r} g_{r k}-\eta_{r}\right)+\sum_{f=1}^{h}\left(w_{f} b_{f k}+\mu_{f}\right) \\
& \text { s.t. } \sum_{i=1}^{m} v_{i} x_{i j}-\sum_{r=1}^{s} u_{r} g_{r j}+\sum_{f=1}^{h} w_{f} b_{f j} \quad \geq 0 \quad(j=1, . ., n) \text {, } \\
& u_{r} g_{r k}+\eta_{r} \quad \geq 1 /(s+h)(r=1, . ., s), \\
& w_{f} b_{f k}+\mu_{f} \quad \geq 1 /(s+h) \quad(f=1, . ., h), \\
& v_{i} \quad \geq \varepsilon_{s} R_{i}^{x} \quad(i=1, . ., m), \\
& u_{r} \quad \geq \varepsilon_{s} R_{r}^{g} \quad(r=1, \ldots, s), \\
& w_{f} \quad \geq \varepsilon_{s} R_{f}^{b} \quad(f=1, . ., h) \&
\end{aligned}
$$

all dual variables $\geq 0$. 
where $v_{i}(i=1, \ldots, m), u_{r}(r=1, \ldots, s), \eta_{r}(r=1, \ldots, s), w_{f}(f=1, \ldots, h)$ and $\mu_{f}(f=1, \ldots$, $h)$ are dual variables (i.e., multipliers) related to the first, second, third, fourth and fifth groups of constraints in Model (1). As formulated in the last three groups of constraints, they are all strictly positive in Model (3). Consequently, the result implies that all production factors are fully utilized in the two models.

The comparison between Models (1) and (3) provides us with the following three concerns: First, the objective value of Model (1) equals that of Model (3) on optimality. Thus, the unified efficiency measure is found from the optimal objective value of Model (3):

$$
\mathrm{UEN}_{c}^{I}=1-\left[\sum_{i=1}^{m} v_{i}^{*} x_{i k}-\sum_{r=1}^{s}\left(u_{r}^{*} g_{r k}-\eta_{r}^{*}\right)+\sum_{f=1}^{h}\left(w_{f}^{*} b_{f k}+\right) \mu_{f}^{*}\right] .
$$

Thus, each dual variable indicates an amount of change in unified inefficiency under natural disposability due to a unit change in the corresponding production factor.

The concept of natural disposability under variable RTS is expressed by the following formulation that slightly reorganizes Model (3):

$$
\begin{array}{ll}
\text { Maximize } & \frac{1}{s+h}\left(\sum_{r=1}^{s} \xi_{r}^{g}+\sum_{f=1}^{h} \xi_{f}^{b}\right)+\varepsilon_{s}\left(\sum_{i=1}^{m} R_{i}^{x} d_{i}^{x-}+\sum_{r=1}^{s} R_{r}^{g} d_{r}^{g}+\sum_{f=1}^{h} R_{f}^{b} d_{f}^{b}\right) \\
\text { s.t. } \quad \text { same constraints in (3) and } \sum_{j=1}^{n} \lambda_{j}=1 .
\end{array}
$$

The incorporation of $\sum_{j=1}^{n} \lambda_{j}=1$ in Model (5) changes the dual formulation (3) as follows:

$$
\begin{array}{ll}
\text { Maximize } & \sum_{i=1}^{m} v_{i} x_{i k}-\sum_{r=1}^{s}\left(u_{r} g_{r k}-\eta_{r}\right)+\sum_{f=1}^{h}\left(w_{f} b_{f k}+\mu_{f}\right)+\sigma \\
\text { s.t. } & \sum_{i=1}^{m} v_{i} x_{i j}-\sum_{r=1}^{s} u_{r} g_{r j}+\sum_{f=1}^{h} w_{f} b_{f j}+\sigma \geq 0 \quad(j=1, \ldots, n) \quad \&
\end{array}
$$

same constraints in (3).

Here, a new dual variable $(\sigma)$, originated from $\sum_{j=1}^{n} \lambda_{j}=1$ in Model (3), is incorporated into Model (6). In the case, the unified efficiency measures are as $\operatorname{UEN}_{v}^{I}$ in this study.

\subsection{Formulations under managerial disposability}

Shifting our interest from natural to managerial disposability, this study changes Model (1) to the following intermediate model under managerial disposability: 


$$
\begin{array}{rlrl}
\text { Maximize } & \frac{1}{s+h}\left(\sum_{r=1}^{s} \xi_{r}^{g}+\sum_{f=1}^{h} \xi_{f}^{b}\right)+\varepsilon_{s}\left(\sum_{i=1}^{m} R_{i}^{x} d_{i}^{x-}+\sum_{r=1}^{s} R_{r}^{g} d_{r}^{g}+\sum_{f=1}^{h} R_{f}^{b} d_{f}^{b}\right) \\
\text { s.t. } \quad & =x_{i k} \quad(i=1, . ., m), \\
& =g_{j=1}^{n} x_{i j} \lambda_{j}-d_{i}^{x+} & (r=1, . ., s), \\
& \sum_{j=1}^{n} g_{r j} \lambda_{j}-d_{r}^{g}-\xi_{r}^{g} g_{r k} & \leq 1 \quad(r=1, . ., s), \\
\xi_{r}^{g} & =b_{f k} \quad(f=1, . ., h), \\
\sum_{j=1}^{n} b_{f j} \lambda_{j}+d_{f}^{b}+\xi_{f}^{b} b_{f k} & \leq 1 \quad(f=1, . ., h), \\
\xi_{f}^{b} & & (j=1, . ., n), \\
\xi_{r}^{g} \geq 0 \quad(r=1, . ., s), \xi_{f}^{b} \geq 0 \quad(f=1, . ., h), \lambda_{j} \geq 0 & \\
d_{i}^{x+} \geq 0 \quad(i=1, . ., m), d_{r}^{g} \geq 0 \quad(r=1, . ., s) \& d_{f}^{b} \geq 0 \quad(f=1, . ., h) .
\end{array}
$$

Model (7) indicates that the $k$ th DMU can attain an efficiency frontier by increasing the amount of inputs under managerial disposability.

The dual formulation of Model (7) is structured as follows:

$$
\begin{array}{rll}
\text { Minimize }-\sum_{i=1}^{m} v_{i} x_{i k}-\sum_{r=1}^{s}\left(u_{r} g_{r k}-\eta_{r}\right)+\sum_{f=1}^{h}\left(w_{f} b_{f k}+\mu_{f}\right) & & \\
\text { s.t. } \quad-\sum_{i=1}^{m} v_{i} x_{i j}-\sum_{r=1}^{s} u_{r} g_{r j}+\sum_{f=1}^{h} w_{f} b_{f j} & \geq 0 & (j=1, . ., n), \\
& & \\
u_{r} g_{r k}+\eta_{r} & \geq 1 /(s+h) & (r=1, . ., s), \\
w_{f} b_{f k}+\mu_{f} & \geq 1 /(s+h) & (f=1, . ., h), \\
v_{i} & \geq \varepsilon_{s} R_{i}^{x} & (i=1, . ., m), \\
& \geq \varepsilon_{s} R_{r}^{g} & (r=1, . ., s), \\
u_{r} & \geq \varepsilon_{s} R_{f}^{b} & (f=1, . ., h) \& \\
w_{f} & &
\end{array}
$$

Here, the description on all dual variables in Model (3) is the same as discussed in Model (8).

A unified efficiency score $\left(\mathrm{UEM}_{c}^{I}\right)$ of the $k$ th DMU under managerial disposability is measured by

$$
\begin{aligned}
\operatorname{UEM}_{c}^{I} & =1-\left[\frac{1}{s+h}\left(\sum_{r=1}^{s} \xi_{r}^{g^{*}}+\sum_{f=1}^{h} \xi_{f}^{b^{*}}\right)+\varepsilon_{s}\left(\sum_{i=1}^{m} R_{i}^{x} d_{i}^{x+^{*}}+\sum_{r=1}^{s} R_{r}^{g} d_{r}^{g^{*}}+\sum_{f=1}^{h} R_{f}^{b} d_{f}^{b^{*}}\right)\right] \\
& =1-\left[\sum_{i=1}^{m} v_{i}^{*} x_{i k}-\sum_{r=1}^{s}\left(u_{r}^{*} g_{r k}-\eta_{r}^{*}\right)+\sum_{f=1}^{h}\left(w_{f}^{*} b_{f k}+\mu_{f}^{*}\right)\right] .
\end{aligned}
$$


The concept of managerial disposability under variable DTS is expressed by the following formulation that slightly reorganizes Model (7):

$$
\begin{aligned}
& \text { Maximize } \frac{1}{s+h}\left(\sum_{r=1}^{s} \xi_{r}^{g}+\sum_{f=1}^{h} \xi_{f}^{b}\right)+\varepsilon_{s}\left(\sum_{i=1}^{m} R_{i}^{x} d_{i}^{x+}+\sum_{r=1}^{s} R_{r}^{g} d_{r}^{g}+\sum_{f=1}^{h} R_{f}^{b} d_{f}^{b}\right) \\
& \text { s.t. } \quad \text { same constraints in (7) and } \sum_{j=1}^{n} \lambda_{j}=1 .
\end{aligned}
$$

The incorporation of $\sum_{j=1}^{n} \lambda_{j}=1$ into Model (10) changes the dual formulation as follows:

$$
\begin{array}{ll}
\text { Minimize } & -\sum_{i=1}^{m} v_{i} x_{i k}-\sum_{r=1}^{s}\left(u_{r} g_{r k}-\eta_{r}\right)+\sum_{f=1}^{h}\left(w_{f} b_{f k}+\mu_{f}\right)+\sigma \\
\text { s.t. } & -\sum_{i=1}^{m} v_{i} x_{i j}-\sum_{r=1}^{s} u_{r} g_{r j}+\sum_{f=1}^{h} w_{f} b_{f j}+\sigma \geq 0(j=1, \ldots, n) \quad \& \\
& \text { same constraints in (8). }
\end{array}
$$

Here, the dual variable $(\sigma)$, originated from $\sum_{j=1}^{n} \lambda_{j}=1$ in Model (10), is incorporated into Model (11). In the case, the unified efficiency is measured as $\mathrm{UEM}_{v}^{I}$.

At the end of this section, it is important to note the three unique features if the proposed intermediate approach. First, this study has discussed a new application of the approach. The research of Sueyoshi et al. (2017b) has provided methodological contribution of the proposed approach by comparing among the intermediate approach and the other two (radial and non-radial) approaches. Second, the proposed approach has an analytical structure, similar to "Russell measure", which methodologically locates between "Debreu-Koopmans efficiency" for radial measurement and "Pareto-Koopmans efficiency" for non-radial measurement in a conventional DEA framework. See Sueyoshi et al. (2017b) for a detailed description on the differences. The difference between the proposed approach and the conventional Russell measure is that the proposed former approach for inefficiency identification can be solved by linear programming and the conventional latter, for efficiency identification, is solved by nonlinear programming. Such differences can increase the level of efficiency measurement by the intermediate approach. See the computational results summarized in Sueyoshi et al. (2017b). A problem of their study is that it does not document any empirical results, just showing an illustrative example for methodical comparison. Such is our empirical contribution of this study. Finally, the intermediate approach incorporates independent efficiency scores for each desirable and undesirable output. The efficiency score can flexibly adjust actual amount of these outputs to shift to optimal ones by the scores. However, I may violate the "efficiency equipment," indicating that an efficiency score should between zero and one. To avoid such a methodological difficulty, the proposed models still use slacks for those outputs. It is easily imagined that it is impossible for us to maintain a practical benefit of the usage without the efficiency equipment. In addition, the restrictions on efficiency scores, that constrain them to be less than or equal unity, are also for such a purpose on the efficiency equipment.

In addition to the above the three methodological concerns, this study needs to discuss on the disposability concepts. This study utilizes natural and managerial disposability concepts that have different priority for efficiency assessment. Under the condition 
with such different priorities, it may be possible that different implications may occur on efficiency scores for desirable outputs and those for undesirable outputs. For example, under the managerial disposability, efficiency scores for undesirable outputs may have higher weight for the purpose of assessment. However, such a weight change on priority does not influence computational results because the proposed approach depends upon linear programming whose optimal solution can be found on an extremal point. The point is often not changed by the weight change. To avoid this type of problem originated from linear programming, it is the best for us, at the current moment, to use the two formulations for disposability, as exhibited in this study.

\section{Empirical results}

To evaluate the sustainability of Asian countries, output variables represent the economic and environmental performance measures and input variables are related to the energy consumption. First, gross domestic product (GDP) is selected to demonstrate the total economic performance and $\mathrm{CO}_{2}$ is selected to present the environmental performance measure at each country level. The consumption of both primary and secondary energies is considered in this study. The primary energy includes traditional energy sources such as crude oil, coal, natural gas, some mineral fuels and renewable energy such as solar, wind, water, biomass, geothermal energy and so on. The secondary energy is an amount of generated electricity. Therefore, the total amount of primary energy and electricity is selected as input variables. Considering differences in population, area, and development status in Asia, this study needs to include the performance to represent the people's living standard in our country comparison. Therefore, the GDP per capita is selected as one of desirable outputs. The amount of $\mathrm{CO}_{2}$ divided by total primary energy is used as an undesirable output.

Thus, this study utilizes the two desirable outputs: GDP and GDP per capita as well as the two undesirable outputs: total $\mathrm{CO}_{2}$ emission and $\mathrm{CO}_{2}$ /total primary energy. The two inputs include electricity consumption and total primary energy consumption. All the production factors are fully used in the proposed DEA application.

We obtain the dataset regarding $\mathrm{CO}_{2}$ emission, total primary energy consumption and electricity consumption from US Energy Information Administration (EIA). The EIA provides a dataset on energy and environment of the whole world in each year from 1980 to 2014. The data on GDP are obtained from Trading Economics (http://www. tradingeconomics.com), and the data on population are obtained from worldometers (http://www.worldometers.info/world-population). The GDP per capita is calculated as an amount of GDP divided by the number of population. This study applies the most recent data in 7 years from 2008 to 2014. Using the dataset, this study examines the 21 countries of Asia after excluding all countries with small $\mathrm{CO}_{2}$ emission and small usage of energy. For example, such excluded nations are Afghanistan, Bhutan, Cambodia, Laos, Macau, Maldives, Nepal and Timor-Leste. Table 1 summarizes descriptive statistics on the dataset.

\subsection{Natural disposability and constant RTS}

Table 2 summarizes the degree of $\operatorname{UEN}_{c}^{I}$ regarding Asian nations from 2008 to 2014 . 
Table 1 Descriptive statistics

\begin{tabular}{|c|c|c|c|c|c|c|}
\hline \multirow{3}{*}{$\begin{array}{l}\text { Year } \\
\text { Unit }\end{array}$} & \multicolumn{2}{|c|}{ Desirable output } & \multicolumn{2}{|c|}{ Undesirable output } & \multicolumn{2}{|l|}{ Inputs } \\
\hline & GDP & GDP/Capita & $\mathrm{CO}_{2}$ & $\begin{array}{l}\mathrm{CO}_{2} / \text { total } \\
\text { energy }\end{array}$ & Electricity & Total energy \\
\hline & $\begin{array}{l}\text { Billion } \\
\text { USD }\end{array}$ & $\begin{array}{l}\text { Thousands } \\
\text { USD }\end{array}$ & $\begin{array}{l}\text { Million metric } \\
\text { tons }\end{array}$ & $\begin{array}{l}\text { Million metric } \\
\text { tons/quadril- } \\
\text { lion Btu }\end{array}$ & $\begin{array}{l}\text { Billion kilowatt } \\
\text { hours }\end{array}$ & Quadrillion Btu \\
\hline \multicolumn{7}{|l|}{2008} \\
\hline Ave. & 696.90 & 13.45 & 566.38 & 61.78 & 281.82 & 7.94 \\
\hline S.D. & 1344.82 & 16.59 & 1483.25 & 11.87 & 665.79 & 18.80 \\
\hline Min. & 5.62 & 0.37 & 1.64 & 26.80 & 1.43 & 0.06 \\
\hline Max. & 4849.18 & 50.20 & 6985.87 & 79.53 & 3071.04 & 87.84 \\
\hline \multicolumn{7}{|l|}{2009} \\
\hline Ave. & 722.41 & 12.35 & 600.62 & 64.06 & 294.88 & 8.32 \\
\hline S.D. & 1443.37 & 15.11 & 1607.74 & 10.60 & 709.27 & 20.13 \\
\hline Min. & 4.58 & 0.44 & 6.45 & 45.37 & 2.03 & 0.09 \\
\hline Max. & 5059.42 & 43.58 & 7573.85 & 84.44 & 3290.29 & 94.29 \\
\hline \multicolumn{7}{|l|}{2010} \\
\hline Ave. & 847.62 & 14.41 & 641.83 & 64.05 & 326.71 & 8.95 \\
\hline S.D. & 1654.38 & 17.53 & 1721.63 & 10.42 & 799.56 & 21.92 \\
\hline Min. & 7.19 & 0.55 & 8.10 & 43.55 & 2.44 & 0.10 \\
\hline Max. & 6039.66 & 53.09 & 8110.66 & 84.54 & 3713.32 & 102.77 \\
\hline \multicolumn{7}{|l|}{2011} \\
\hline Ave. & 974.68 & 16.56 & 689.09 & 63.88 & 353.26 & 9.46 \\
\hline S.D. & 1932.48 & 20.29 & 1897.54 & 9.81 & 895.10 & 23.90 \\
\hline Min. & 10.41 & 0.60 & 8.41 & 43.14 & 3.03 & 0.10 \\
\hline Max. & 7492.43 & 63.86 & 8951.16 & 80.16 & 4178.91 & 112.37 \\
\hline \multicolumn{7}{|l|}{2012} \\
\hline Ave. & 1036.90 & 17.15 & 714.31 & 63.42 & 366.39 & 9.83 \\
\hline S.D. & 2096.58 & 20.95 & 1958.82 & 8.87 & 945.38 & 25.12 \\
\hline Min. & 12.29 & 0.64 & 8.60 & 45.55 & 3.45 & 0.14 \\
\hline Max. & 8461.62 & 67.67 & 9222.34 & 78.01 & 4434.91 & 118.22 \\
\hline \multicolumn{7}{|l|}{2013} \\
\hline Ave. & 1048.42 & 17.32 & 695.58 & 63.77 & 390.48 & 9.62 \\
\hline S.D. & 2199.35 & 20.97 & 1936.42 & 8.65 & 1030.68 & 25.08 \\
\hline Min. & 6.01 & 0.04 & 7.92 & 42.97 & 3.73 & 0.14 \\
\hline Max. & 9607.22 & 67.61 & 9151.47 & 77.23 & 4845.68 & 118.50 \\
\hline \multicolumn{7}{|l|}{2014} \\
\hline Ave. & 1085.52 & 17.14 & 695.76 & 64.06 & 405.14 & 9.74 \\
\hline S.D. & 2341.33 & 20.26 & 1909.30 & 8.73 & 1076.74 & 25.24 \\
\hline Min. & 6.06 & 0.04 & 9.09 & 41.99 & 3.95 & 0.16 \\
\hline Max. & $10,482.37$ & 61.61 & 9017.78 & 75.79 & 5066.78 & 119.26 \\
\hline \multicolumn{7}{|l|}{ Total } \\
\hline Ave. & 916.06 & 15.48 & 657.65 & 63.57 & 345.53 & 9.12 \\
\hline S.D. & 1861.26 & 18.67 & 1761.30 & 9.75 & 870.11 & 22.57 \\
\hline Min. & 4.58 & 0.04 & 1.64 & 26.80 & 1.43 & 0.06 \\
\hline Max. & $10,482.37$ & 67.67 & 9222.34 & 84.54 & 5066.78 & 119.26 \\
\hline
\end{tabular}


Table 2 Unified efficiency under natural disposability and constant RTS

\begin{tabular}{|c|c|c|c|c|c|c|c|c|}
\hline & 2008 & 2009 & 2010 & 2011 & 2012 & 2013 & 2014 & Average \\
\hline \multicolumn{9}{|l|}{ 1st Tier } \\
\hline Japan & 0.8941 & 0.9448 & 0.9880 & 1.0000 & 1.0000 & 0.8675 & 0.8269 & 0.9316 \\
\hline Brunei & 0.8898 & 0.7264 & 0.7851 & 1.0000 & 0.9665 & 1.0000 & 0.9119 & 0.8971 \\
\hline New Zealand & 0.7351 & 0.6928 & 0.8261 & 0.9086 & 0.9035 & 1.0000 & 1.0000 & 0.8666 \\
\hline \multicolumn{9}{|l|}{ 2nd Tier } \\
\hline Australia & 0.7368 & 0.6295 & 0.7727 & 0.9039 & 0.9637 & 1.0000 & 0.9493 & 0.8509 \\
\hline Singapore & 0.6850 & 0.5960 & 0.7467 & 0.8145 & 0.8336 & 1.0000 & 0.9321 & 0.8011 \\
\hline Hong Kong & 0.6581 & 0.6211 & 0.6430 & 0.7187 & 0.7723 & 0.8560 & 1.0000 & 0.7528 \\
\hline \multicolumn{9}{|l|}{ 3rd Tier } \\
\hline Sri Lanka & 0.4239 & 0.4159 & 0.5152 & 0.6232 & 0.6569 & 1.0000 & 1.0000 & 0.6622 \\
\hline China & 0.4857 & 0.4995 & 0.5400 & 0.5911 & 0.6341 & 0.6902 & 1.0000 & 0.6343 \\
\hline Burma (Myanmar) & 0.3922 & 0.5213 & 0.6465 & 0.4988 & 0.5038 & 0.4566 & 0.7586 & 0.5397 \\
\hline \multicolumn{9}{|l|}{ 4th Tier } \\
\hline Korea, South & 0.3943 & 0.3528 & 0.4005 & 0.4071 & 0.4083 & 0.4486 & 0.4982 & 0.4157 \\
\hline India & 0.3216 & 0.3354 & 0.4000 & 0.4158 & 0.3985 & 0.4199 & 0.4438 & 0.3907 \\
\hline Indonesia & 0.3073 & 0.3102 & 0.3589 & 0.3777 & 0.3720 & 0.3680 & 0.3574 & 0.3502 \\
\hline Philippines & 0.2881 & 0.2745 & 0.3194 & 0.3483 & 0.3798 & 0.3947 & 0.3972 & 0.3431 \\
\hline Taiwan & 0.2878 & 0.2987 & 0.3132 & 0.3207 & 0.3312 & 0.3419 & 0.3484 & 0.3203 \\
\hline \multicolumn{9}{|l|}{ 5th Tier } \\
\hline Pakistan & 0.1834 & 0.1738 & 0.1838 & 0.2454 & 0.2407 & 0.2480 & 0.2638 & 0.2199 \\
\hline Malaysia & 0.2028 & 0.1747 & 0.2021 & 0.2379 & 0.2428 & 0.2360 & 0.2370 & 0.2190 \\
\hline Bangladesh & 0.2344 & 0.2429 & 0.2700 & 0.2835 & 0.2713 & 0.0117 & 0.0118 & 0.1894 \\
\hline Thailand & 0.1544 & 0.1429 & 0.1638 & 0.1788 & 0.1890 & 0.1854 & 0.1784 & 0.1704 \\
\hline Mongolia & 0.0906 & 0.0702 & 0.1033 & 0.1571 & 0.1943 & 0.1376 & 0.1169 & 0.1243 \\
\hline Vietnam & 0.1055 & 0.1096 & 0.0961 & 0.1156 & 0.1280 & 0.1501 & 0.1555 & 0.1229 \\
\hline Korea, North & 0.0226 & 0.0208 & 0.0252 & 0.0388 & 0.0385 & 0.0456 & 0.0416 & 0.0333 \\
\hline
\end{tabular}

Both Japan and New Zealand belong to the top tier group in the unified efficiency measures

The 1st tier includes Japan, Brunei and New Zealand that have outperformed the other countries with $\mathrm{UEN}_{c}^{I}$ over 0.8666 on average. Japan keeps the top rank in the performance measure. All of the $\mathrm{UEN}_{c}^{I}$ were above 0.8269 and the average was 0.9316. Japan is a developed country with a high standard of living and leads the Asian economy for a long time in history. It is still on the leading position. Brunei experienced a huge economic growth during 1990s and 2000s since its independence from the UK, with GDP increasing 56\% from 1999 to 2008, transformed Brunei into an industrialized country. It has developed wealth from extensive petroleum and natural gas fields. In 2011, Brunei was one of the two countries with a public debt at $0 \%$ of the national GDP. Thus, Brunei maintains a high standard of living and economic performance with the level of $\mathrm{UEN}_{c}^{I}$ at 0.8971 on average in the 7 years. The $\operatorname{UEN}_{c}^{I}$ decreased from 0.8898 in 2008 to 0.7264 in 2009 , which was seriously influenced by the global financial crisis. Then, the degree of $\mathrm{UEN}_{c}^{I}$ grew back to 0.7851 in 2010. Brunei recovered in 2011 with the $\mathrm{UEN}_{c}^{I}$ of 1, fluctuated a little to 0.9665 in 2012 and kept the level at 1 in 2013. The $\operatorname{UEN}_{c}^{I}$ decreased to 0.9119 in 2014. New Zealand has a high-income economy and extractive industries have contributed strongly to its economy, historically focusing on sealing, whaling, flax, gold, kauri gum and native timber. The average $\mathrm{UEN}_{c}^{I}$ was 0.8666 . It decreased from 0.7351 to 0.6928 in 2009 due to the financial crisis in 2008. However, it gradually grew to 1 in 2013 
and maintained the high level in 2014. Thus New Zealand showed the strong position in its economic recovery and growth.

The 2nd tier includes Australia, Singapore and Hong Kong that are ranked in the second top tier in their unified efficiency measures. The averages of $\mathrm{UEN}_{c}^{I}$ were between 0.7528 and 0.8509 . Australia is a wealthy country that generates the income from various sources such as mining-related exports, telecommunications, banking and manufacturing. The economy was drastically pulled down by the financial crisis in 2008 , with the $\mathrm{UEN}_{c}^{I}$ decreasing from 0.7368 to 0.6295 . However, Australia recovered very quickly with $6-15 \%$ growth of $\operatorname{UEN}_{c}^{I}$ every year and reached 1 in 2013. The Australia's economy slightly decreased with the $\operatorname{UEN}_{c}^{I}$ back to 0.9493 in 2014 . Thus, Australia's economy fluctuates within a steadily increase, indicating the economic potential of Australia. Singapore is a global commerce, finance and transport hub. Based on extended trade, Singapore has a highly developed market economy. Along with Hong Kong, South Korea and Taiwan, Singapore is one of the original Four Asian Tigers. It has surpassed the others in terms of economic performance with $\mathrm{UEN}_{c}^{I} 0.8011$ on average in the 7 years. The $\mathrm{UEN}_{c}^{I}$ dropped from 0.6850 in 2008 to 0.5960 in 2009 due to the financial crisis in 2008 . Then, it jumped to 0.7467 in 2010 and continued to grow to 1 in 2013 . The $\operatorname{UEN}_{c}^{I}$ slightly dropped to 0.9321 in 2014. Hong Kong is one of the world's most significant financial centers with the highest financial development index score and consistently ranks as the world's most competitive and freest economic entity. The $\mathrm{UEN}_{c}^{I}$ was 0.7528 on average in the 7 years. The $\operatorname{UEN}_{c}^{I}$ kept at the level around 0.6407 on average from 2008 to 2010 and fast grew to 1 in 2014. Hong Kong was significantly attacked by finance crisis of 2008 because its economy relies on the finance.

The 3rd tier includes Sri Lanka, China and Burma (Myanmar) that are classified to the third tier with $\mathrm{UEN}_{c}^{I}$ between 0.5397 and 0.6622 on average in 7 years. Sri Lanka is impressive because the $\mathrm{UEN}_{c}^{I}$ drastically increased from 0.4239 to 1 , which made average $\mathrm{UEN}_{c}^{I}$ at 0.6622 . In particular, in 2012-2013, the $\mathrm{UEN}_{c}^{I}$ jumped from 0.6569 to 1 . Sri Lanka has long maritime borders and beautiful view. The country's main economic sectors are tourism, tea export, clothing, and agriculture products. When we check the original data, the GDP increased from $\$ 40$ to $\$ 80$ billion in the observed 7 years and the GDP per capita increased from $\$ 12$ to $\$ 17.4$ thousand. Thus, Sri Lanka's economy is transitioning to the efficiency-driven stage in the recent years. China is the world's second largest economy by GDP and largest by purchasing power parity (PPP). Even though China has become one of the world's fastest-growing major economies in the current years and has crucial global influence power on economy, the large population drags down the average living standard of Chinese people. Because a desirable output of this study included GDP per capita, the China's economy was classified into the third tier with $\mathrm{UEN}_{c}^{I} 0.6343$ on average. It reflects the relatively poor living standard of people, comparing to its good economy at the country level. Unlike the countries with better performance, China's economy was so strong and was not impacted by the financial crisis of 2008. The $\mathrm{UEN}_{c}^{I}$ fast grew from 0.4857 in 2008 to 1 in 2014. Burma (Myanmar) is a country rich in jade and gems, oil, natural gas and other mineral resources. However, the income gap is the widest in the world, as a large proportion of the economy is controlled by supporters of the former military government. Moreover, political and economic ideological struggles have affected living standards. Therefore, the economy is 
classified into the third tier according to the average living standard. The $\mathrm{UEN}_{c}^{I}$ increased from 0.3922 to 0.6465 from 2008 to 2010. The government of Burma was undergoing a critical transition during the annual periods. The $\mathrm{UEN}_{c}^{I}$ decreased to 0.4988 in 2011 and kept at this level 0.5038 in 2012. The nation continued to drop to 0.4566 in 2013 and 0.7586 in 2014. In 2011, Myanmar started economic liberalization and formed a draft foreign investment law in 2012.

The 4th tier includes South Korea, India, Indonesia, Philippines and Taiwan that hold the degree of $\mathrm{UEN}_{c}^{I}$ at the level between 0.3203 and 0.4157 on average in the observed 7 years.

South Korea's economy soared at an annual average of $10 \%$ for over 30 years. The degree of $\operatorname{UEN}_{c}^{I}$ was 0.4157 on average. South Korea had the $\operatorname{UEN}_{c}^{I} 0.3943$ in 2008. Though the $\mathrm{UEN}_{c}^{I}$ decreased to 0.3528 in 2009 due to the financial crisis, it increased back to 0.4005 and continued to increase slowly to 0.4982 in 2014. India became one of the fastest-growing major economies, and it is now considered a newly industrialized country. The service sectors, including information technology and software services, had an annual growth rate of above $9 \%$ since 2001. India ranks second worldwide in farm output. However, India is the second-most populous country, which pushed the people's living standard low on average with the average $\mathrm{UEN}_{c}^{I}$ at 0.3907 . The $\mathrm{UEN}_{c}^{I}$ has gradually increased from 0.3216 in 2008 to 0.4438 in 2014. Indonesia has the largest economy by GDP in Southeast Asia and considered as emerging markets and newly industrialized country with $\mathrm{UEN}_{c}^{I}$ at 0.3502 on average. The $\mathrm{UEN}_{c}^{I}$ increased from 0.3073 in 2008 to 0.3777 in 2011 and gradually decreased back to 0.3574 in 2014. Even though the economy grew from 0.3073 to 0.3574 from 2008 to 2014 in general, the decreasing trend was observed after 2011. Philippines is a sovereign island country in the western Pacific Ocean with average $\operatorname{UEN}_{c}^{I}$ at 0.3431 . The $\mathrm{UEN}_{c}^{I}$ slowly increased from 0.2881 in 2008 to 0.3972 in 2014.

Taiwan entered a period of rapid economic growth and industrialization since 1960. The high-tech industry plays a key role in the global economy. However, the growth pace was down in recent years with $\operatorname{UEN}_{c}^{I}$ at 0.3203 on average. Therefore, Taiwan's economy grew steadily and slowly in recent years with $\mathrm{UEN}_{c}^{I}$ that increased from 0.2878 in 2008 to 0.3484 in 2014.

The 5th tier includes all the remaining countries consist of the last tier, having the $\mathrm{UEN}_{c}^{I}$ below 0.2199 on average and grew slowly in terms of economy. Among them, Pakistan and Malaysia performed relatively better with average $\operatorname{UEN}_{c}^{I}$ at 0.2199 and 0.2190 , respectively. North Korea was really poor with average $\mathrm{UEN}_{c}^{I}$ at 0.0333 even if the $\mathrm{UEN}_{c}^{I}$ had been doubled in the 7 years.

The implication, obtained from Table 2, implies that most of the countries grew slowly in terms of the unified efficiency under natural disposability and constant RTS. There are two groups of exception. First, China, New Zealand, Sri Lanka and Hong Kong kept rapid growth since 2008 and the $\mathrm{UEN}_{c}^{I}$ reached 1 in 2014. Second, some countries, including Japan, Australia, Singapore and Brunei, faced an economic meltdown after the growth. Among them, Japan's economy started to turn down after 2012 and faced the pitfall in recent years. The $\mathrm{UEN}_{c}^{I}$ decreased from 1 in 2012 to 0.8675 in 2013 and continued to decreased to 0.8269 in 2014, both of which were the smallest during the 7 years. The disaster of Fukushima Daiichi nuclear plants occurred on March 11, 2011, seriously 
Table 3 Unified efficiency under managerial disposability and constant DTS

\begin{tabular}{|c|c|c|c|c|c|c|c|c|}
\hline & 2008 & 2009 & 2010 & 2011 & 2012 & 2013 & 2014 & Average \\
\hline \multicolumn{9}{|l|}{ 1stTier } \\
\hline Japan & 0.9081 & 0.9589 & 1.0000 & 1.0000 & 0.9691 & 0.8724 & 0.8322 & 0.9344 \\
\hline New Zealand & 0.7008 & 0.6681 & 0.8393 & 1.0000 & 0.8954 & 1.0000 & 1.0000 & 0.8719 \\
\hline \multicolumn{9}{|l|}{ 2ndTier } \\
\hline Brunei & 0.6994 & 0.6341 & 0.6502 & 0.8689 & 0.8816 & 1.0000 & 0.8289 & 0.7947 \\
\hline Australia & 0.6409 & 0.5500 & 0.6979 & 0.8523 & 0.9144 & 0.9572 & 0.9127 & 0.7893 \\
\hline China & 0.4865 & 0.5092 & 0.5698 & 0.6306 & 0.7461 & 0.8706 & 1.0000 & 0.6875 \\
\hline \multicolumn{9}{|l|}{ 3rd Tier } \\
\hline Singapore & 0.5676 & 0.4161 & 0.5736 & 0.6056 & 0.6181 & 0.6257 & 0.6303 & 0.5767 \\
\hline Hong Kong & 0.4887 & 0.4378 & 0.4337 & 0.4821 & 0.5483 & 0.6257 & 0.6556 & 0.5245 \\
\hline Korea, South & 0.4977 & 0.4967 & 0.5145 & 0.4821 & 0.4844 & 0.4815 & 0.5076 & 0.4949 \\
\hline Burma (Myanmar) & 0.2383 & 0.4080 & 0.4824 & 0.5904 & 0.5988 & 0.5205 & 0.5259 & 0.4806 \\
\hline Sri Lanka & 0.3903 & 0.3686 & 0.4774 & 0.4983 & 0.5031 & 0.5151 & 0.5043 & 0.4653 \\
\hline Taiwan & 0.3773 & 0.4065 & 0.4036 & 0.3831 & 0.3854 & 0.3918 & 0.3953 & 0.3919 \\
\hline India & 0.3312 & 0.3345 & 0.3735 & 0.3968 & 0.3806 & 0.4041 & 0.4337 & 0.3792 \\
\hline \multicolumn{9}{|l|}{ 4th Tier } \\
\hline Indonesia & 0.2490 & 0.2506 & 0.3288 & 0.3690 & 0.3591 & 0.3485 & 0.3237 & 0.3184 \\
\hline Philippines & 0.2525 & 0.2504 & 0.2908 & 0.3145 & 0.3527 & 0.3704 & 0.3722 & 0.3148 \\
\hline Malaysia & 0.2945 & 0.2931 & 0.2935 & 0.3054 & 0.3036 & 0.2936 & 0.2999 & 0.2977 \\
\hline Thailand & 0.2855 & 0.2847 & 0.2836 & 0.2962 & 0.3121 & 0.2961 & 0.2989 & 0.2939 \\
\hline Pakistan & 0.2766 & 0.2760 & 0.2812 & 0.2735 & 0.2743 & 0.2756 & 0.2719 & 0.2756 \\
\hline Vietnam & 0.2319 & 0.2530 & 0.2256 & 0.2527 & 0.2639 & 0.2713 & 0.3973 & 0.2708 \\
\hline Bangladesh & 0.2430 & 0.2415 & 0.2561 & 0.2725 & 0.2581 & 0.2525 & 0.2567 & 0.2544 \\
\hline Korea, North & 0.1831 & 0.1789 & 0.1815 & 0.1899 & 0.1887 & 0.1939 & 0.1857 & 0.1860 \\
\hline Mongolia & 0.1515 & 0.1433 & 0.1375 & 0.1553 & 0.1909 & 0.1848 & 0.1897 & 0.1647 \\
\hline
\end{tabular}

devastated Japan's economy. The impact was revealed from 2012. The other three economies, Brunei, Australia and Singapore, slightly dropped from 2013 to 2014 with the $\mathrm{UEN}_{c}^{I}$ decreasing from 1 in 2013 to $0.9119,0.9493$ and 0.9321, respectively, in 2014.

\subsection{Managerial disposability and constant DTS}

Table 3 summarizes the $\operatorname{UEM}_{c}^{I}$ on 21 Asian countries from 2008 to 2014.

The 1st tier includes Japan and New Zealand that have the $\mathrm{UEM}_{c}^{I}$ over 0.8719 on average in 7 years. Japan had the average $\operatorname{UEM}_{c}^{I}$ at 0.9344 and maintained a high level of unified efficiency. The $\mathrm{UEM}_{c}^{I}$ increased from 0.9081 in 2008 to 1 in 2010 and maintained the perfect performance at 1 in 2011. However, the $\mathrm{UEM}_{c}^{I}$ started a decreasing trend to 0.9691 in 2012 and reached to $0.8724,0.8322$ in 2013 and 2014, gradually. As mentioned previously, such a decreasing trend was because of the Fukushima Daiichi nuclear disaster that drastically damaged the Japanese energy usage and environment conditions. New Zealand had the $\mathrm{UEM}_{c}^{I}$ at 0.8719 on average in the 7 years. The $\mathrm{UEM}_{c}^{I}$ fast increased from 0.7008 in 2008 to 1 in 2014 except a drop to 0.8954 in 2012. Thus, New Zealand has spending a considerable policy effort for environmental improvement.

The 2nd tier includes Brunei, Australia and China that consist of the second tier in $\mathrm{UEM}_{c}^{I}$ between 0.6875 and 0.7947 on average in the 7 years. Brunei's performance on environment fluctuated slightly in recent years, but $\operatorname{UEM}_{c}^{I}$ did not change seriously and 
kept at the level above 0.6502 from 2008 to 2010 and 0.8289 to 0.8816 in recent 4 years except 1 in 2013. The $\mathrm{UEM}_{c}^{I}$ of Australia decreased from 0.6409 in 2008 to 0.5500 in 2009 and jumped back to 0.6979 in 2010. It continued to increase to 0.9572 in 2013 and dropped back to 0.9127 in 2014. Similar as the economy, Australia's performance slightly fluctuated, but still kept at a high level. China fast grew with $\mathrm{UEM}_{c}^{I}$ from 0.4865 in 2008 to 1 in 2014, and the average $\operatorname{UEM}_{c}^{I}$ was 0.6875 . This indicates the Chinese effort for developing, implementing and enforcing a solid environment law framework.

The 3rd tier includes Singapore, Hong Kong, South Korea, Burma (Myanmar), Sri Lanka, Taiwan and India that are classified to this tier, with the $\operatorname{UEM}_{c}^{I}$ between 0.3792 and 0.5767 on average in the 7 years. Singapore had the level of $\operatorname{UEM}_{c}^{I}$, gradually increasing from 0.5676 in 2008 to 0.6303 in 2014 except the drop by $15 \%$ in 2009. It outperformed the other three "Tiger economies" (i.e., Hong Kong, South Korea and Taiwan) in environmental perspective. Most of nations in this tier were impacted by the financial crisis of 2008 in terms of their environmental performance measures, except Burma having $17 \%$ increase in 2009. Taiwan and India had small increases. Burma (Myanmar) fast increased the $\mathrm{UEM}_{c}^{I}$ from 0.2383 in 2008 to 0.5988 in 2012 and dropped to 0.5205 in 2013 and 0.5259 in 2014. Taiwan basically maintained the degree of $\mathrm{UEM}_{c}^{I}$ at the level around 0.3773 to 0.3953 . The increase was very small, indicating that Taiwan's development stagnated in recent years. India gradually increased $\mathrm{UEM}_{c}^{I}$ from 0.3312 in 2008 to 0.4337 in 2014 except $1 \%$ drop in 2012. India paid much attention on its economic prosperity, not developing a balanced development between economy and environment protection.

The 4th tier includes all rest countries that had $\mathrm{UEM}_{c}^{I}$ below 0.3184 on average in the observed 7 year. North Korea and Mongolia still performed the worst in environmental protection with the average $\mathrm{UEM}_{c}^{I}$ below 0.2 .

The implication, obtained from Table 3, implies that Japan and New Zealand leaded all Asian nations in both economic and environmental performance measures because they were in first tier under both natural disposability and managerial disposability. Brunei and Australia developed in balance with economic growth and environment protection by controlling $\mathrm{CO}_{2}$ emission and maintained their performance measures at a high level. China fast grew in past decades and tried to catch up with developed countries. It showed a huge potential to lead the Asia in future. All "Tiger" economies, including Singapore, South Korea, Hong Kong and Taiwan, declined in both economy and environment. All countries in the fifth tier in economic performance belonged to the last tier in environmental performance, as well. Thus, the underdeveloped countries have a long way to develop the balanced economy and environment, especially North Korea and Mongolia.

At the end of this section, we need to note that the degree of $\operatorname{UEN}_{v}^{I}$ and that of $\mathrm{UEM}_{v}^{I}$ on 21 Asian countries from 2008 to 2014 have similar results as documented in Tables 2 and 3. Therefore, similar policy implication discussed from Tables 2 and 3 may be obtained from the ones in the cases. For example, the huge population may be the rationale concerning decreased $\mathrm{UEM}_{v}^{I}$ in China and India. This indicates that they need challenging policy to reduce industrial pollutions in developing their economies. Hence, this study does not document their results to reduce the length of this manuscript. 


\section{Conclusion and future extensions}

To methodologically combat the climate change, this study proposed a new use of DEA for assessing a level of social sustainability. DEA was separated into "radial" or "nonradial" category by Sueyoshi and Goto (2018) and Sueyoshi et al. (2017a). A methodological contribution of this study is that it newly proposes an "intermediate approach" that analytically locates between the two categories. The intermediate approach was first proposed by Sueyoshi and Yuan (2017). See also Sueyoshi et al. (2017b).

As an application, this study used the proposed approach for measuring the social sustainability of 21 Asian nations from 2008 to 2014. They have been developing their economic prosperities in a short period, but currently suffering from various pollutions. The performance assessment on Asian nations is important because they are most growing areas on energy consumptions and economic developments in the world. All Asian nations examined in this study were classified into four or five groups based upon their unified efficiency measures under natural disposability and managerial disposability.

An important implication was that among Asian nations, Japan and New Zealand belonged to the first tier group in terms of their social sustainability developments. Japan's economy started to turn down after 2012 and faced the pitfall in recent years. Japan has been a leading nation in Asia even after the disaster of Fukushima Daiichi nuclear plants occurred on March 11, 2011. The disaster has seriously devastated Japan's economy and energy structure. Meanwhile, New Zealand has developed its economy by exporting agriculture products and maintained its natural beauty. Thus, the two nations belonged to the top group by the four unified efficiency measures. Thus, it is recommended that the other Asian nations may pay attention to their industrial and environmental developments. The other important implication is that large nations such as China and India have not badly performed if we consider the size of their economies. This is a surprising result because they are large carbon emitters in the world and thereby they have been often criticized in the international community.

It is indeed true that this study is not perfect. Here, four issues need to be discussed here. First, the proposed intermediate approach needs to be explored a time horizon, which is not explored in this study. See Sueyoshi et al. (2017a). Second, it is necessary for us to apply the intermediate approach to other industrial nations in Europe, the USA and Japan, not only Asia as explored in this research. Such tasks will be important future extensions of this study. Third, this study has used two inputs such electricity consumption and total primary energy consumption to compute our efficiency scores. Some portion of total primary energy consumption is used for electricity generation. See Sueyoshi and Goto (2018). A rationale on these usages is that they are important sources of desirable outputs such as GDP. See Sueyoshi and Goto (2018) for empirical evidence on the rationale. Finally, the nations analyzed in this study are considerably different in their industry structures. Under such variations, relationships between GDP and $\mathrm{CO}_{2}$ emissions are influenced by the industry structures. This study has not incorporated these structural differences. The issue will be explored as a future research task.

Finally, it is hoped that this study makes a contribution in DEA intermediate approach applied to energy and environment. We look forward to seeing future developments as specified in this research. 


\section{Additional file}

Additional file 1. Data.

\section{Authors' contributions}

TS proposed the models and wrote the theoretical part. YY collected the data, did the computational analysis and wrote the empirical part. Both authors read and approved the final manuscript.

\section{Acknowledgements}

This is original research which has not been discussed in any conference and reviewed by other researchers. The comments and suggestions are appreciated.

\section{Competing interests}

There is no financial or non-financial competing interest in relation to this work.

Availability of data and materials

Please see Additional file 1 for data.

Ethics approval and consent to participate

Not applicable.

\section{Funding}

The authors declare that there is not any funding for this research.

\section{Publisher's Note}

Springer Nature remains neutral with regard to jurisdictional claims in published maps and institutional affiliations.

Received: 29 August 2017 Accepted: 17 December 2017

Published online: 08 February 2018

\section{References}

Chaitip P, Chaiboonsri C, Inluang F (2014) The production of Thailand's sugarcane: using panel data envelopment analysis (panel DEA) based decision on bootstrapping method. Procedia Econ Finance 14:120-127

Chen CC (2017) Measuring departmental and overall regional performance: applying the multi-activity DEA model to Taiwan's cities/counties. Omega 67:60-80

Honma S, Hu J-L (2008) Total-factor energy efficiency of regions in Japan. Energy Policy 36:821-833

Honma S, Hu J-L (2014) Industry-level total-factor energy efficiency in developed countries: a Japan-centered analysis. Appl Energy 119:67-78

Hosseinzadeh A, Smyth R, Valadkhani A, Le V (2016) Analyzing the efficiency performance of major Australian mining companies using bootstrap data envelopment analysis. Econ Model 57:26-35

Li K, Lin B (2016) Impact of energy conservation policies on the green productivity in China's manufacturing sector: evidence from a three-stage DEA model. Appl Energy 168:351-363

Sueyoshi T, Goto M (2012) DEA environmental assessment of coal fired power plants: methodological comparison between radial and non-radial models. Energy Econ 34:1854-1863

Sueyoshi T, Goto M (2018) Environmental assessment on energy and sustainability by data envelopment analysis. Wiley, London

Sueyoshi T, Yuan Y (2017) Social sustainability measured by intermediate approach for DEA environmental assessment: Chinese regional planning for economic development and pollution prevention. Energy Econ 66:154-166

Sueyoshi T, Goto M, Wang D (2017a) Index measurement on frontier shift for sustainability enhancement by Chinese provinces. Energy Econ 67:554-571

Sueyoshi T, Yuan Y, Goto M (2017b) A literature survey for DEA environmental assessment on energy and sustainability. Energy Econ 62:104-124

Sueyoshi T, Yuan Y, Li A, Wang D (2017c) Methodological comparison among radial, non-radial and intermediate approaches for DEA environmental assessment. Energy Econ 67:39-453

Sun J, Wu J, Guo D (2013) Performance ranking of units considering ideal and anti-ideal DMU with common weights. Appl Math Model 37:6301-6310

Tun YY, Kang H-J (2015) An analysis on the factors affecting rice production efficiency in Myanmar. J East Asian Econ Integr 19:167-188

Ullah A, Perret SR, Gheewala SH, Soni P (2016) Eco-efficiency of cotton-cropping systems in Pakistan: an integrated approach of life cycle assessment and data envelopment analysis. J Clean Prod 134(Part B):623-632

Yang W-C, Lee Y-M, Hu J-L (2016) Urban sustainability assessment of Taiwan based on data envelopment analysis. Renew Sustain Energy Rev 61:341-353 